\title{
THE EFFECT OF DIFFERENT REMINERALIZING AGENTS ON LASER BLEACHED ENAMEL
}

\author{
Aya Elsayed Samaha* and Dina Hazem Hassan Gomaa**
}

\begin{abstract}
One of the most required esthetic measures for patients with teeth discoloration or those who strive to have a beautiful smile and appearance is bleaching. The objective of this study is to analyze enamel morphological changes, chemical composition and microhardness following the application of $35 \%$ hydrogen peroxide, utilizing two various protocols for laser activation and the application of 4 different remineralizing agents.
\end{abstract}

Materials and methods: In this study, 40 extracted human lateral and central incisors were chosen where the researcher categorized teeth into 2 groups consisting of 20 incisors, using two different laser-activated bleaching protocols. The researcher then subdivided each group into 4 subsets consisting each of 5 incisors where 4 remineralizing agents were applied to each bleached subset. Enamel surface morphology was studied by ESEM. Calcium and Phosphorus content were measured by EDAX and microhardness Vicker's test was performed to study the alteration in enamel hardness. Pre- and post-demineralization (bleaching) investigations were conducted and then they were repeated following remineralization.

Results: ESEM revealed the improvement of enamel surface morphology in the remineralized groups except in (HD) and (LD) groups. After remineralization, all groups had a higher weight percent of calcium $(\mathrm{Ca})$ and phosphorus $(\mathrm{P})$ levels than its levels after demineralization except in groups (HD) and Vicker's hardness number in all groups showed significant increase except (HD) and (LD).

Conclusion: The use of remineralizing agents containing casein phosphopeptide-amorphous calcium phosphate, fluoride or hydroxyapatite nanoparticles could improve the enamel morphology, microhardness and chemical composition of laser bleached enamel.

\section{INTRODUCTION}

Nowadays, dentistry and society have a key concern which is represented by esthetics ${ }^{[1]}$. There are a number of methods for managing the discoloration of tooth including veneers, crowns, and the bleaching of teeth. Treatments using crowns and veneers are subjected to a significant dental hard tissue loss. Vital bleaching of teeth costs less compared to bonded restorative dentistry, in addition, it is con-

\footnotetext{
* BDS, MSc, DDS, Operative Dentistry Department, Faculty of Dentistry, Ain Shams University

** BDS, MSc, DDS, Oral Biology Department, Faculty of Dentistry, Ain Shams University
} 
sidered a non-invasive and conservative method that finds good acceptance as a safer and more effective technique ${ }^{[2]}$. Today, many different systems of bleaching have been introduced to meet this need ${ }^{[3]}$. Currently, different modalities of treatment are existing including in-office bleaching (professionally administered), dentist supervised takehome bleaching (professionally dispensed), and over-the-counter bleaching (self-administered ${ }^{[4]}$. A proven effective technique for lightening the color of teeth is in-office bleaching.

Apart from the employed method or product, bleaching agents' mechanism of action is dependent on a complicated oxidation process with releasing species of reactive oxygen that can penetrate into the pores of enamel rods till it reaches to the dentin, resulting in the breakdown of organic molecules and the production of clearer, smaller, and lighter compounds ${ }^{[5]}$. The majority of clinical studies revealed that above $70 \%$ of patients undergone in-office bleaching have complains about tooth sensitivity. Such sensitivity is the key barrier that prevents patients from completing their bleaching treatment successfully ${ }^{[6]}$. Trying to reduce or confine the dental sensitivity while bleaching, numerous agents were presented in order to be utilized pre- or post- bleaching or they can be utilized in combination with bleaching gels ${ }^{[7]}$. Moreover, morphological changes in the enamel; as erosion, craters and porosities; have been observed by various authors after bleaching [8],[9],[10]. Yet, these defects can be reconditioned by applying remineralizing agents ${ }^{[11]}$ including calcium, fluoride, hydroxyapatite, and amorphous calcium phosphate in order to reduce the negative impacts resulting on the enamel after the bleaching treatment ${ }^{[12]}$. It is possible to add these components to the bleaching gel for preventing the enamel demineralization while bleaching and for reducing the dental sensitivity reveled by several patients ${ }^{[13]}$. But there exist conflicting results regarding bleaching agents' influences on altering dental tissues' surface morphology and chemical features ${ }^{[13]}$.
A much faster and more convenient method to prevent enamel surface roughness in the first place might be the irradiation of the bleaching agent using diode lasers ${ }^{[15]}$.There is scare and controversial evidence on the impact of laser protection on bleached enamel. However, this field is quite new and open to investigation. It seems that the application of diode laser at both wavelengths of 810 and $980 \mathrm{~nm}$ might reduce the extent of enamel surface alteration that happens during bleaching ${ }^{[16]}$.

Due to the scarcity of studies that compared desensitizing agents' impact on the capability of bleaching gels and on the structure of enamel ${ }^{[12,17]}$, this study was conducted to assess the impacts of various remineralizing protocols on enamel morphology, microhardness and human enamel's chemical composition in vitro after laser activation of the bleaching agent.

\section{MATERIALS AND METHODS:}

\section{1- Collection of human teeth (Enamel speci- mens' preparation):}

Forty freshly extracted sound human upper central and lateral incisors were chosen in the current study. Teeth were obtained from the Department of Oral and Maxillofacial, Faculty of Dentistry, University of Ain-Shams. After cleaning and disinfecting the teeth, they were stored in fresh, renewed deionized water at $4{ }^{\circ} \mathrm{C}{ }^{[18]}$ until the beginning of the experimental procedure. Then, under light stereomicroscope (SZ-PT OLYMPUSJAPAN), examinations were applied to teeth to exclude those having cracks, abrasions or decay. There was standardization through the use of the same tooth as a control to be investigated before and after treatment.

By utilizing (double-face) diamond disks (MANI, Inc Japan), teeth were sectioned $2 \mathrm{~mm}$ below the cemento-enamel junction level under copious water spray coolant in the Laboratory of Oral Biology Department, Faculty of Dentistry, University of Ain-Shams. Double adhesive tapes were placed on 
a glass slab where the specimens were attached to it with the buccal surface facing downward, polyvinyl chloride rings (PVC) $19 \mathrm{~mm}$ in diameter were placed over the prepared specimens. Fast set chemical cured acrylic resin (Acrostone, Egypt) was poured into PVC rings and left to harden.

The remnants of the double adhesive tape were eliminated from the enamel surface. Finally, the buccal side was flattened by utilizing $\mathrm{SiC}$ paper grits \#320 and \#400 polished with \#600,\#1200 and \#2400 grit by utilizing wet abrasive paper (latexed waterproof paper brown aluminum oxide electro coated, China) for 30s for each one in a circular motion. The specimens were ultrasonically cleaned for 5 minutes.

\section{2- Initial microhardness analysis:}

Enamel microhardness was evaluated for all the specimens using Digital Vicker's hardness tester (Nexus 4000TM, INNOVA TEST, model no 4503 , Netherlands) with a $100 \mathrm{gm}$ load. A tetra pyramidal diamond indenter was employed for making indentation on the flat surface of enamel with allowing the loaded diamond to be submerged and rest on the surface of the enamel for $10 \mathrm{~s}$.

\section{3- Environmental scanning electron microscopy (ESEM) analysis:}

The enamel surfaces were scanned using ESEM magnification x5000 (SEM Model Quanta 250 Field Emission Gun (FEG) connected with "Energy Dispersive X-ray Analyses" Unit (EDX) with 30 K.V. acceleration voltage, magnification $14 \mathrm{x}$ up to 1000000 and resolution for Gun.1n, FEI company, Netherlands) at The Egyptian Mineral Resources Authority, Central Laboratories Sector, Giza, Egypt. Electronmicrographs were obtained at 30 kilovoltage (KV) using secondary electron live fiber detection (LFD) detector under the magnification of $(1000 x-5000 x)$ with a spot size $(4.7-5.3 \mathrm{~nm})$ for each sample.

\section{4-Quantitative analysis of surface mineral con- tent of enamel samples by EDAX:}

To chemically analyze and measure calcium (Ca) and phosphorus (P) weight \% of each enamel sample, S- UTW detector (EDAX Inc., Mahwah, NJ, United States of America) combined with EDAX (Energy Dispersive X-ray Analyzer) was utilized. Placed under vacuum, each sample of enamel was excited to a higher state of energy with an electron beam. Since each element's electrons fall back down to their original state of energy, they send emissions of $\mathrm{x}$-ray energy at various specified lengths of waves. Each of these elements was identified by its known wave length on the $\mathrm{x}$-axis represented by a peak and the intensity of the peak on the $y$-axis determines the amount of the element.

\section{5- Specimens grouping and bleaching procedures (demineralization):}

For this study, two different laser bleaching protocols were selected $(\mathrm{n}=20)$; $7 \mathrm{~W}$ high laser power for 30s $(\mathrm{H})$ according to the manufacturer recommendation and $1.5 \mathrm{~W}$ low laser power for $90 \mathrm{~s}$ (L), 30s at a time with a rest period in between for $1.5 \mathrm{~s}{ }^{[16]}$.

The Photon Plus $980 \mathrm{~nm}$ Zolar diode laser was utilized in this study (Zolar technology \&Manufacturing Co.Inc Mississauga, ON Canada) in a continuous mode. The delivery of the laser beam to the handpiece of bleaching was carried out by an optic fiber at a 2-mm distance from the surface. The laser energy output's area for the handpiece of whitening was 2.9 $\mathrm{cm}^{2}$. Using the Gentec powermeter (i.e. Gentec electrooptique Inc., QC, Canada), the power of output was measured before the irradiation of laser.

Heydent (GmbH, Kaufering, Germany), was the bleaching gel used in the form of a $5 \mathrm{~g}$ dual syringe that is composed of $35 \%$ hydrogen peroxide bleaching gel and activator in 4:1 ratio. The clamp and cap of the syringe were removed and replaced with a mixing tip. The gel was squeezed until a homogenous colored mass of the gel was obtained. 
Placing the bleaching gel in a uniform layer on the surface of enamel of each specimen, it was followed by the irradiation of laser according to the previous grouping. Using running water for a period of $15 \mathrm{~s}$ to rinse the gel off the surfaces of the enamel, it was reapplied in the same manner according the bleaching protocol applied.

\section{6- Post bleaching analysis:}

Immediately after bleaching, the Vickers hardness measurements as well as ESEM and the quantitative analysis of the surface mineral content were performed in the same experimental conditions of the baseline measurement.

\section{7- Specimens grouping and remineralization protocol:}

In accordance with the utilized remineralizing material, the specimens in groups $(\mathrm{H})$ and $(\mathrm{L})$ were randomly sub-divided into 4 categories $(\mathrm{n}=5)$ as follows: 1) D/Sense (D) (Centrix, Shelton, USA) which is a one-step dual action desensitizing agent that is composed of potassium binoxalate and nitric acid in wate, 2) GC MI Paste Plus ( C) (GC, Tokyo, Japan) )which is a water based cream of $\mathrm{pH} 7.8$ that contains fluoride-incorporated Recaldent (Casein Phosphopeptide-amorphous Calcium Phosphate Fluoride (CPP-ACPF), 3) hydroxyapatite nanoparticles (Ha) and 4) Flor-Opal ${ }^{\circledR}(\mathrm{F})$ (Ultradent, South Jordan, USA) which is a sustained release, $0.5 \%$ fluoride ion in a sticky, clear high viscosity gel with a $\mathrm{pH} 6.5$.

The gel in all (D) groups was applied by agitation and left in place for $2 \mathrm{~min}$, while for the (C) groups, the paste was applied in a uniform layer for 5 minutes on the surface of the enamel of the specimen. The hydroxyapatite nanoparticles used in (Ha) groups were prepared using the wet chemical technique as shown by ${ }^{[19],[20]}$ of calcium nitrate with ammonium hydroxide ((NH4)HPO4). Through altering the HA precipitation' time and temperature, the size of grain was under control where the values of $\mathrm{pH}$ ranged from 10 to 12 and the reaction was performed at room temperature .The final product was a white powder with rod shape particles(as seen under TEM) and average size of L $90 \pm 10 \mathrm{~nm}, \mathrm{~W}$ $20 \pm 5 \mathrm{~nm}$. Nanoparticles were prepared by Nanotech Company for photo-electronics (dreamland, $6^{\text {th }}$ October, Egypt). The prepared paste was applied on the specimen followed by scrubbing using a microbrush for 10s and then it was left undisturbed for 4 minutes. Finally, the gel in all (F) groups was applied in a uniform layer for $30 \mathrm{~min}$ as recommended by the manufacturer on the enamel surface of the specimens.

\section{8- Post remineralization analysis:}

Immediately after the remineralization with different agents and specimens' rinsing, the Vickers hardness measurements, ESEM, as well as the quantitative analysis of the content of surface mineral were taken under the same experimental conditions of the baseline and post bleaching measurements.

\section{RESULTS}

\section{SEM Analysis (Scanning Electron Microscopy):}

The score of treated and untreated enamel's superficial morphology was described as follows: enamel that presents a smooth surface containing small number of scratches; the surface of enamel that presents inconsiderable irregularities; the surface of enamel that presents modest irregularities; the surface of enamel that presents accentuated irregularities; the surface of enamel that presents low deposition of granular structures; and the surface of enamel that presents granular structure's accentuated deposition of ${ }^{[21]}$.

A smooth surface was shown by non-bleached samples (Fig 1). After bleaching, (H) groups showed slight morphological alterations of the enamel surfaces characterized by small irregularities (Fig 2). While, (L) samples showed moderate superficial alterations of enamel surface characterized by moderate irregularities in the form of depressions and erosions, with emphasized interprismatic spaces (Fig 3). 
After remineralization, (HD) specimens showed the fish scale appearance of enamel rods. No deposits were found (Fig 4). The topography of surface of (HC) revealed granular structures' accentuated deposition (Fig 5), whereas (HHa) enamel surfaces revealed granular structures' superficial deposition (Fig 6). Finally, the surfaces of (HF) enamel showed moderate superficial deposits (Fig 7).

Specimens bleached with laser power $1.5 \mathrm{~W}$ revealed the characteristic fish scale appearance in parts of the enamel and others with the normal appearance of the superficial enamel surface with no deposit in (LD) samples (Fig 8). On the other hand, enamel surfaces showed accentuated, superficial

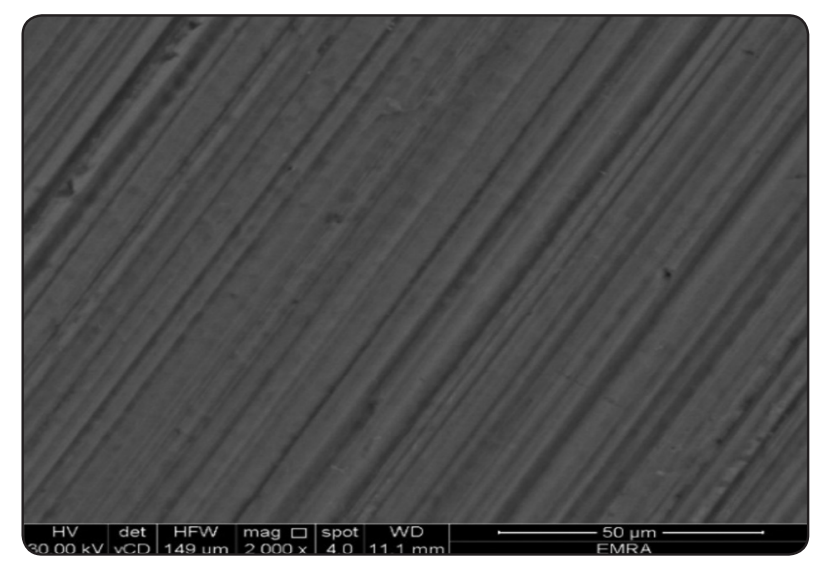

Fig. (1) ESEM micrograph (2000x) of control group: showing enamel with smooth surface and few scratches.

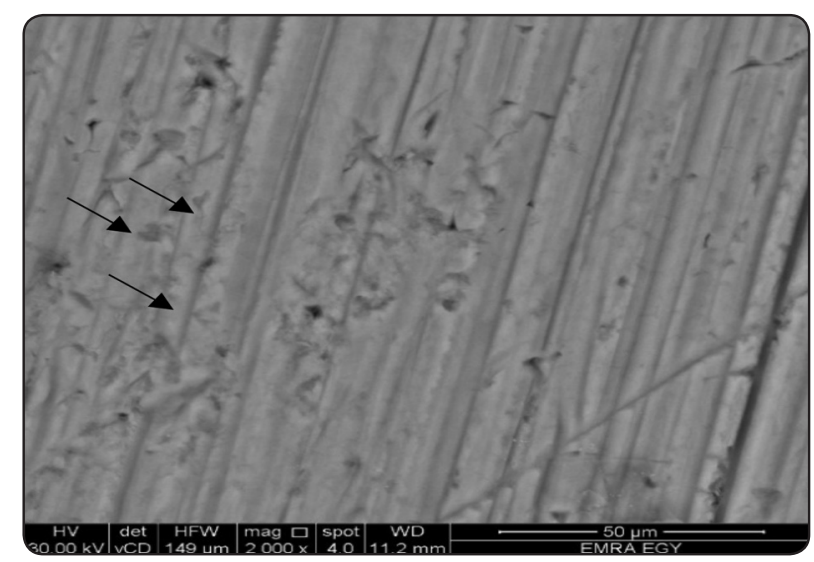

Fig. (3) ESEM micrograph (2000x) of (L) group: Enamel surface showing moderate irregularities with depressions and erosions (arrows). and moderate deposition of granular structures in (LC), (LHa) and (LF) groups respectively (Fig 9, 10 and 11).

\section{Quantitative Enamel Surface Mineral Content Analysis}

On the surface of enamel, the analysis was conducted before, after bleaching and after remineralization to determine the levels of $\mathrm{Ca}$ (calcium) and $\mathrm{P}$ (phosphorous) in enamel surface layer in each group. The findings revealed that there aren't statistical significant differences in the level of Ca upon comparison between all groups (Tables 1,2 and Figures 12,13).

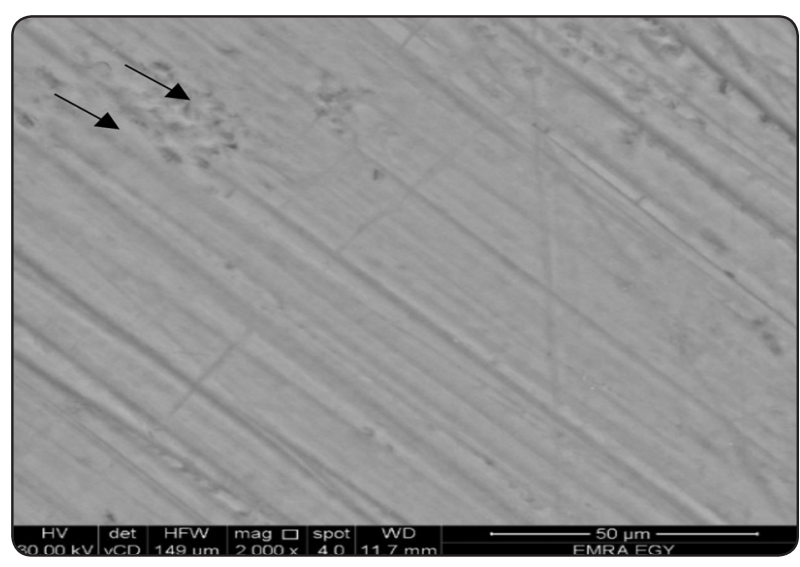

Fig. (2) ESEM micrograph (2000x) of (H) group: Enamel surface showing slight irregularities (arrows).

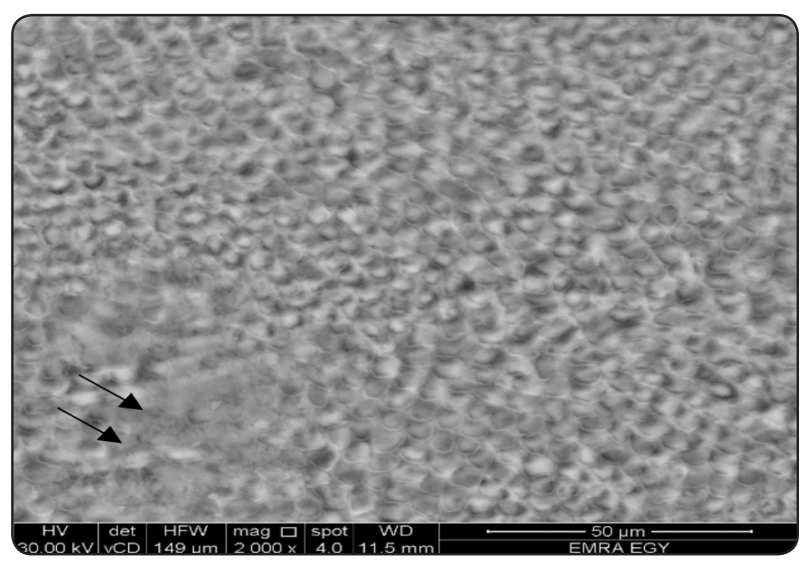

Fig. (4) ESEM micrograph (2000x) of (HD) group: Enamel showing fish scale appearance of enamel rods with areas of destruction of interprismatic spaces (arrows). 


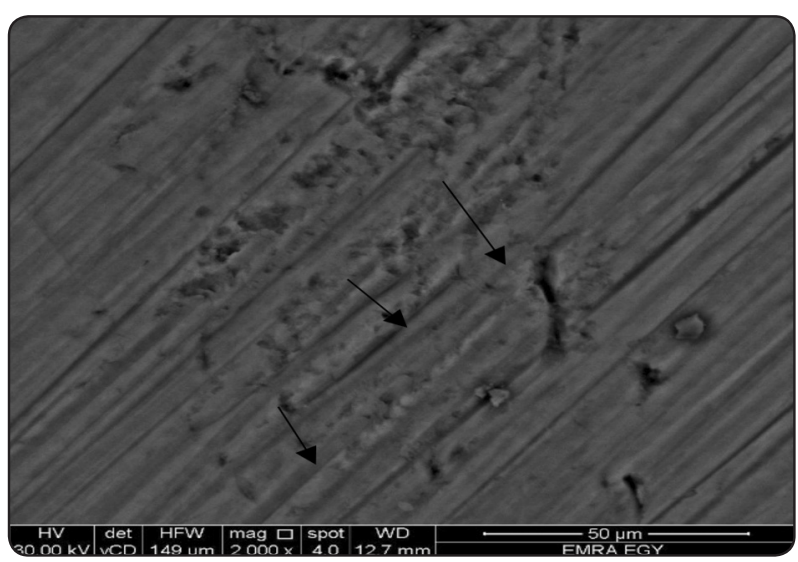

Fig. (5) ESEM micrograph (2000x) of (HC) group: Enamel surfaces showing granular structures' accentuated deposition (arrows).

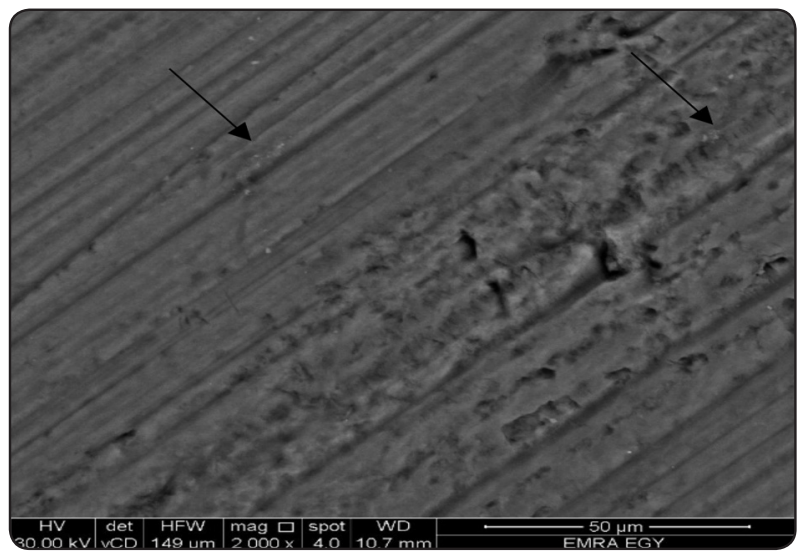

Fig. (7) ESEM micrograph (2000x) of (HF) group: Enamel surface showing moderate deposition of granular structures (arrows).

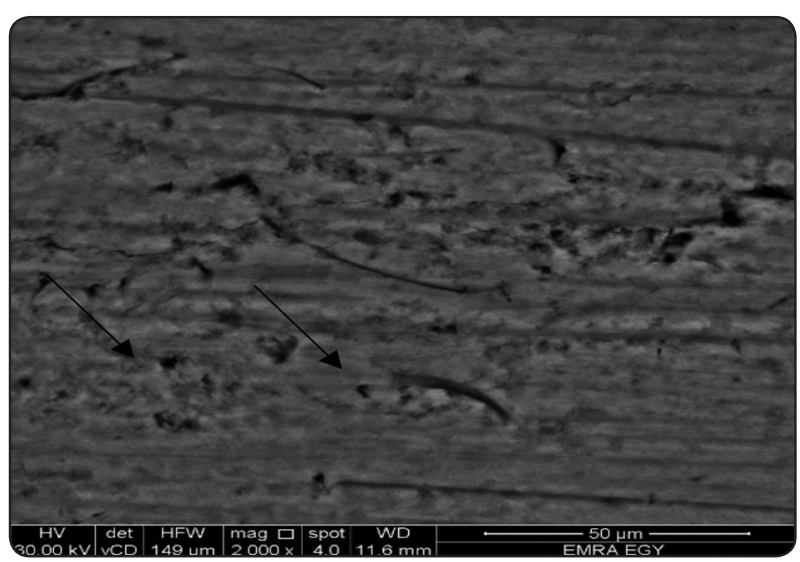

Fig. (9) ESEM micrograph (2000x) of (LC) group: the surface of enamel revealing granular structures' accentuated deposition (arrows).

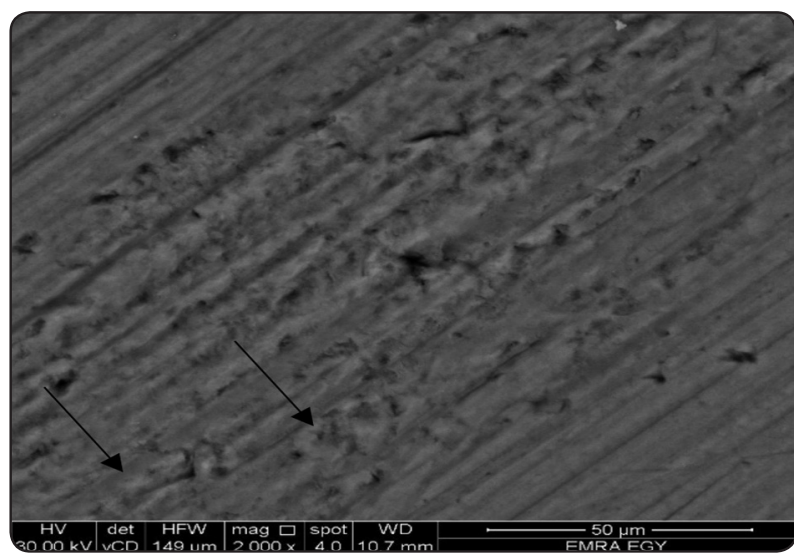

Fig. (6) ESEM micrograph (2000x) of (HHa) group: Enamel surfaces revealing granular structures' superficial deposition (arrows).

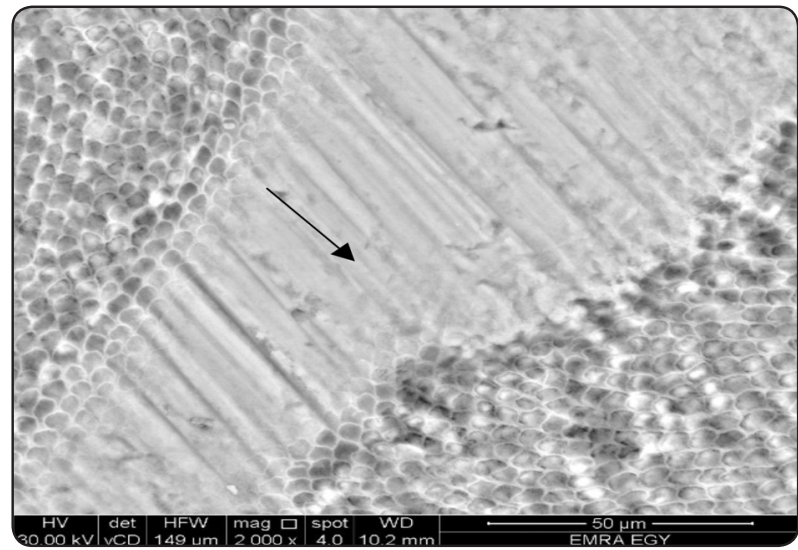

Fig. (8) ESEM micrograph (2000x) of (LD) group: Parts of the enamel showing the characteristic fish scale appearance with areas of destruction of interprismatic spaces (arrows).

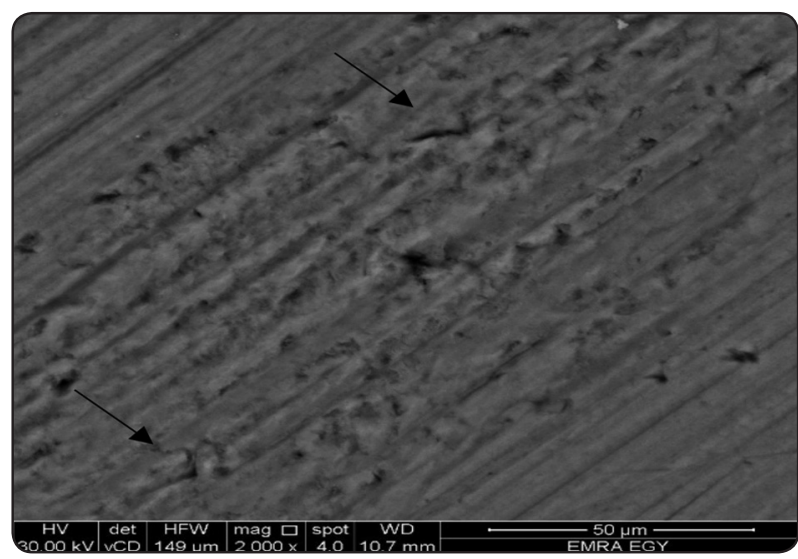

Fig. (10) ESEM micrograph (2000x) of (LHa) group: Enamel surface revealing granular structures' superficial deposition (arrows). 


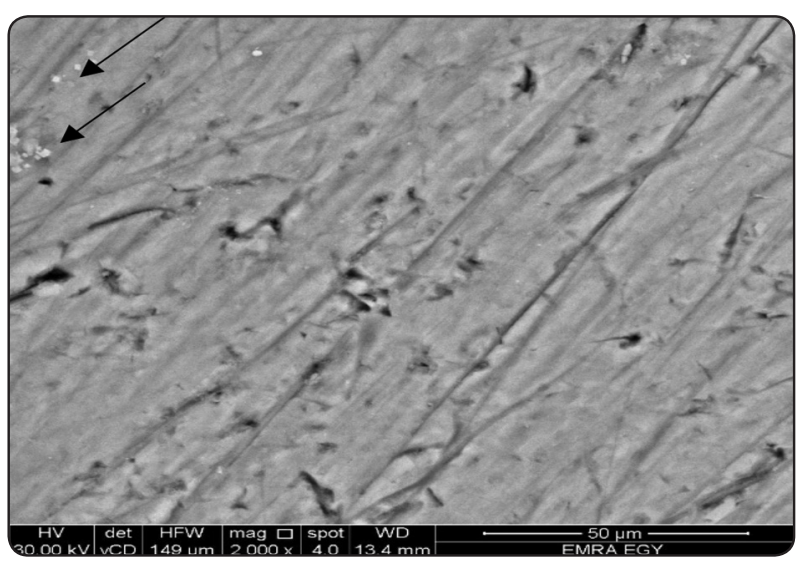

Fig. (11) ESEM micrograph (2000x) of (LF) group: Enamel surface showing granular structures' moderate deposition (arrows).
After remineralization, group (HD) showed the lowest weight percent of $\mathrm{Ca}$ level when compared to the baseline and demineralization levels, while groups (HC), (HHa), (HF), (LC), (LHa) had a higher weight percent of $\mathrm{Ca}$ level than its level after demineralization but less than the baseline level. Meanwhile, groups (LD) and (LF) showed the highest weight percent of $\mathrm{Ca}$ level after remineralization. As for the P levels, groups (HD), (HC) and (HF) showed the lowest weight percent of $\mathrm{P}$ level when compared to the baseline and demineralization levels, while groups (HHa), (LHa), and (LF)had a higher weight percent of $\mathrm{P}$ level than its level after demineralization but less than the baseline level. Meanwhile, groups (LC) and (LF) showed the highest weight percent of $P$ level after remineralization.

TABLE (1): Mean weight percent of Ca content in all samples.

\begin{tabular}{|c|c|c|c|c|c|c|c|c|}
\hline \multirow[b]{2}{*}{ Group } & \multirow[b]{2}{*}{ Treatment } & \multicolumn{2}{|c|}{ Baseline } & \multicolumn{2}{|c|}{ Demineralization } & \multicolumn{2}{|c|}{ Remineralization } & \multirow{2}{*}{$\mathrm{P}$ value } \\
\hline & & Mean & Std. Deviation & Mean & Std. Deviation & Mean & Std. Deviation & \\
\hline \multirow{4}{*}{$\mathrm{H}$} & HD & 45.3450 & .74246 & 45.1750 & .98288 & 44.8950 & .19092 & 0.615 \\
\hline & $\mathrm{HC}$ & 45.1200 & .04243 & 44.6900 & .26870 & 44.8650 & .74246 & 0.625 \\
\hline & HHa & 44.3250 & .00707 & 43.7200 & .31113 & 44.0900 & .72125 & 0.408 \\
\hline & $\mathrm{HF}$ & 45.0900 & .29698 & 43.8200 & .18385 & 44.5050 & 1.27986 & 0.447 \\
\hline \multirow{4}{*}{$\mathrm{L}$} & LD & 44.4300 & .00000 & 43.9650 & .31820 & 45.3750 & .02121 & 0.11 \\
\hline & $\mathrm{LC}$ & 45.2250 & .64347 & 44.6700 & .22627 & 44.9600 & .32527 & 0.236 \\
\hline & LHa & 45.1800 & .79196 & 43.9150 & .75660 & 45.1700 & .28284 & 0.417 \\
\hline & LF & 45.1800 & 1.28693 & 44.1800 & .22627 & 45.4750 & .14849 & 0.438 \\
\hline
\end{tabular}

One was Anova showed no significant value.

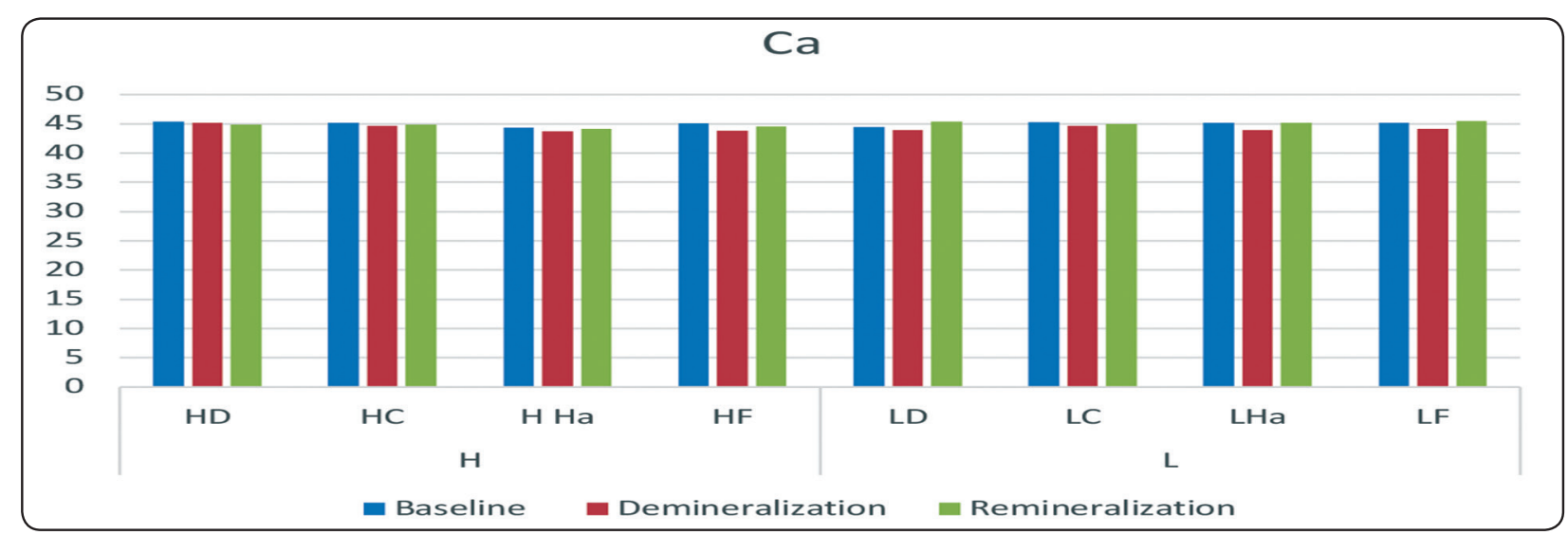

Fig. (12): Mean weight percent of Ca content among samples in all groups. 
TABLE (2): Mean weight percent of $\mathrm{P}$ content in all samples.

\begin{tabular}{|c|c|c|c|c|c|c|c|c|}
\hline \multirow[b]{2}{*}{ Group } & \multirow[b]{2}{*}{ Treatment } & \multicolumn{2}{|c|}{ Baseline } & \multicolumn{2}{|c|}{ Demineralization } & \multicolumn{2}{|c|}{ Remineralization } & \multirow[t]{2}{*}{$P$ value } \\
\hline & & Mean & Std. Deviation & Mean & Std. Deviation & Mean & Std. Deviation & \\
\hline \multirow[t]{4}{*}{$\mathrm{H}$} & HD & 21.0600 & .05657 & 20.9450 & .00707 & 19.9400 & .35355 & 0.135 \\
\hline & $\mathrm{HC}$ & 20.7150 & .79903 & 20.5850 & .02121 & 20.4450 & .34648 & 0.905 \\
\hline & НHa & 20.6950 & .34648 & 20.0900 & .28284 & 20.1900 & .09899 & 0.216 \\
\hline & $\mathrm{HF}$ & 20.5000 & .29698 & 20.3700 & .45255 & 20.1350 & .13435 & 0.575 \\
\hline \multirow[t]{4}{*}{$\mathrm{L}$} & LD & 20.4150 & .24749 & 20.5300 & .35355 & 20.5700 & .91924 & 0.975 \\
\hline & $\mathrm{LC}$ & 20.4550 & .20506 & 20.2150 & .23335 & 20.7300 & .16971 & 0.056 \\
\hline & LHa & 20.3300 & .18385 & 20.1800 & .26870 & 20.2900 & .09899 & 0.374 \\
\hline & $\mathrm{LF}$ & 20.9550 & .26163 & 20.6500 & .29698 & 20.8300 & .12728 & 0.146 \\
\hline
\end{tabular}

One way Anova showed no significant value.

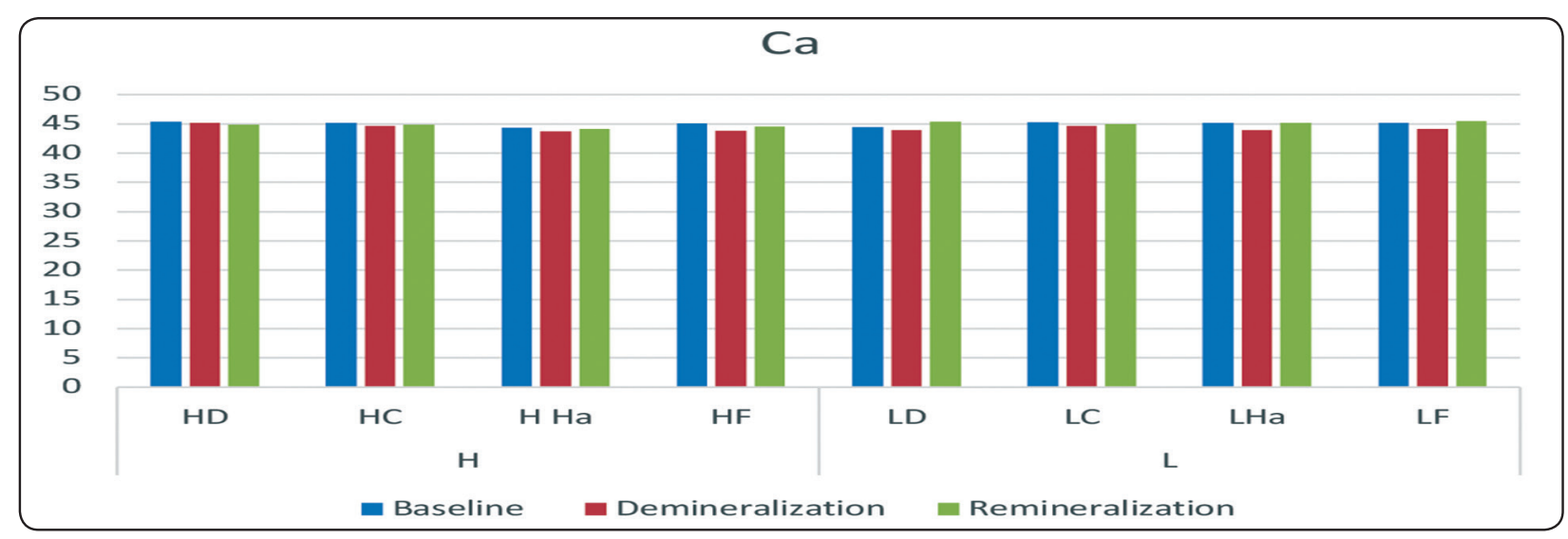

Fig. (13): Mean weight percent of $\mathrm{P}$ content among samples in all groups.

\section{Microhardness evaluation:}

One way Anova was utilized followed by tukey post hock test if it was statistically significant. Anova for repeated measures was used for comparison within groups followed by lsd post hock test. The level of significance was defined at $\mathrm{P} \leq 0.05$, with using IBM ${ }^{\circledR}$ SPSS $\AA^{\circ}$ Statistics Version 20 for Windows to perform the statistical analysis.

Table 3 shows the Vickers Hardness Numbers (VHN). ANOVA for repeated measures showed significant difference within all groups. Within group (HC), (LHa) and (LF) post hock test revealed that there a significant difference between demineralization and both baseline and remineralization. Within group (LC) post hock test revealed that there a significant difference between remineralization and demineralization but showed no statistical difference with the baseline. Within the oxalate groups, post hock test revealed that there is a significant difference between baseline, demineralization and remineralization (Fig 14, 15). 
TABLE (3): Means and standard deviations of Vickers hardness number (VHN) among the experimental groups before and after bleaching and after remineralization.

\begin{tabular}{|c|c|c|c|c|c|c|c|c|}
\hline \multirow[b]{2}{*}{ Group } & \multirow[b]{2}{*}{ Treatment } & \multicolumn{2}{|c|}{ Baseline } & \multicolumn{2}{|c|}{ Demineralization } & \multicolumn{2}{|c|}{ Remineralization } & \multirow[t]{2}{*}{$P$ value } \\
\hline & & Mean & Std. Deviation & Mean & Std. Deviation & Mean & Std. Deviation & \\
\hline \multirow[t]{4}{*}{$\mathrm{H}$} & HD & 364.258 & 17.22874 & 330.5780 & 14.16212 & 170.3640 & 108.33981 & 0.004 \\
\hline & $\mathrm{HC}$ & $365.236^{\mathrm{a}}$ & 9.04683 & 322.904 & 8.33756 & $365.038^{\mathrm{a}}$ & 6.92722 & $<0.001$ \\
\hline & $\mathrm{HHa}$ & $371.956^{\mathrm{a}}$ & 19.42357 & 327.844 & 6.66498 & 375.3560 & 12.70232 & 0.001 \\
\hline & $\mathrm{HF}$ & $371.436^{\mathrm{a}}$ & 8.51702 & $336.258^{\mathrm{a}}$ & 7.50893 & $375.850^{\mathrm{a}}$ & 22.85159 & 0.004 \\
\hline \multirow[t]{4}{*}{$\mathrm{L}$} & LD & 364.378 & 16.51044 & 327.872 & 15.31919 & 188.28 & 91.93877 & 0.003 \\
\hline & $\mathrm{LC}$ & $357.422^{\mathrm{ab}}$ & 19.53157 & $350.924^{\mathrm{a}}$ & 27.48913 & $391.258^{\mathrm{b}}$ & 22.42955 & 0.032 \\
\hline & LHa & $358.704^{\mathrm{a}}$ & 17.47243 & 337.6040 & 20.56366 & $380.258^{\mathrm{a}}$ & 7.75067 & 0.001 \\
\hline & $\mathrm{LF}$ & $370.844^{\mathrm{a}}$ & 10.76729 & 335.1820 & 9.31722 & $375.464^{\mathrm{a}}$ & 9.21264 & 0.001 \\
\hline
\end{tabular}

Different letters in the same row indicate statistically significant differences $(\mathrm{p}<0.05)$

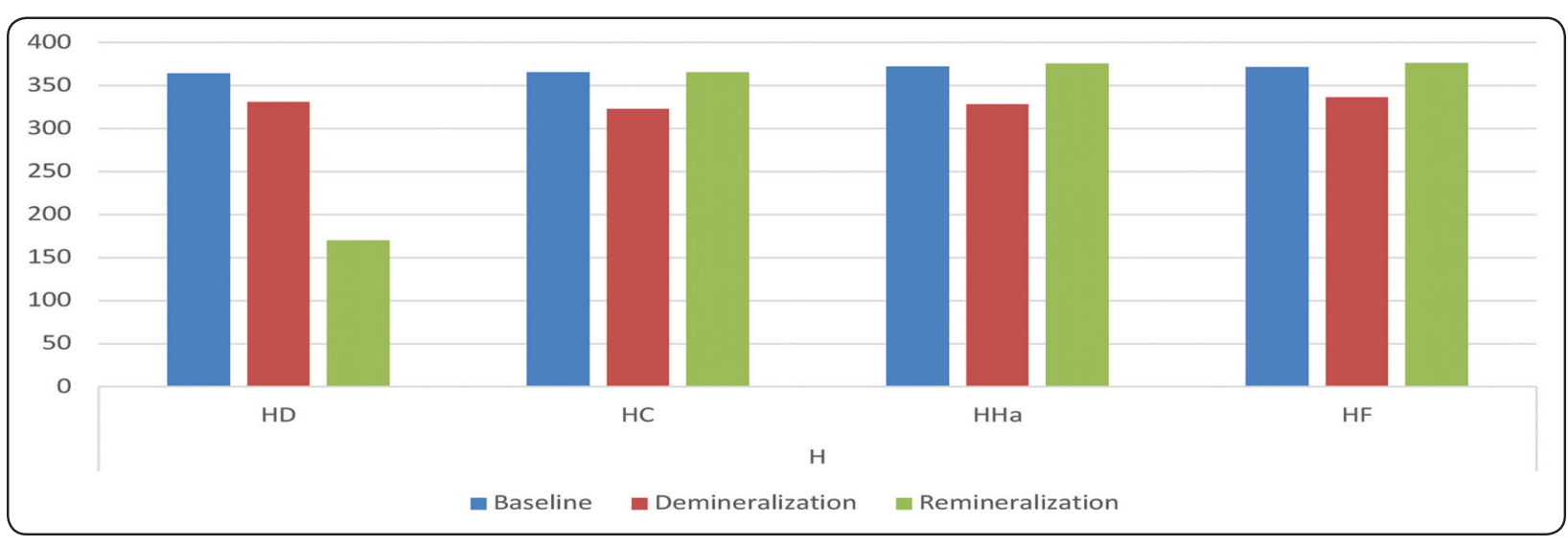

Fig. (14): Mean Vickers hardness number upon bleaching with 7W and remineralizing with different remineralizing agents.

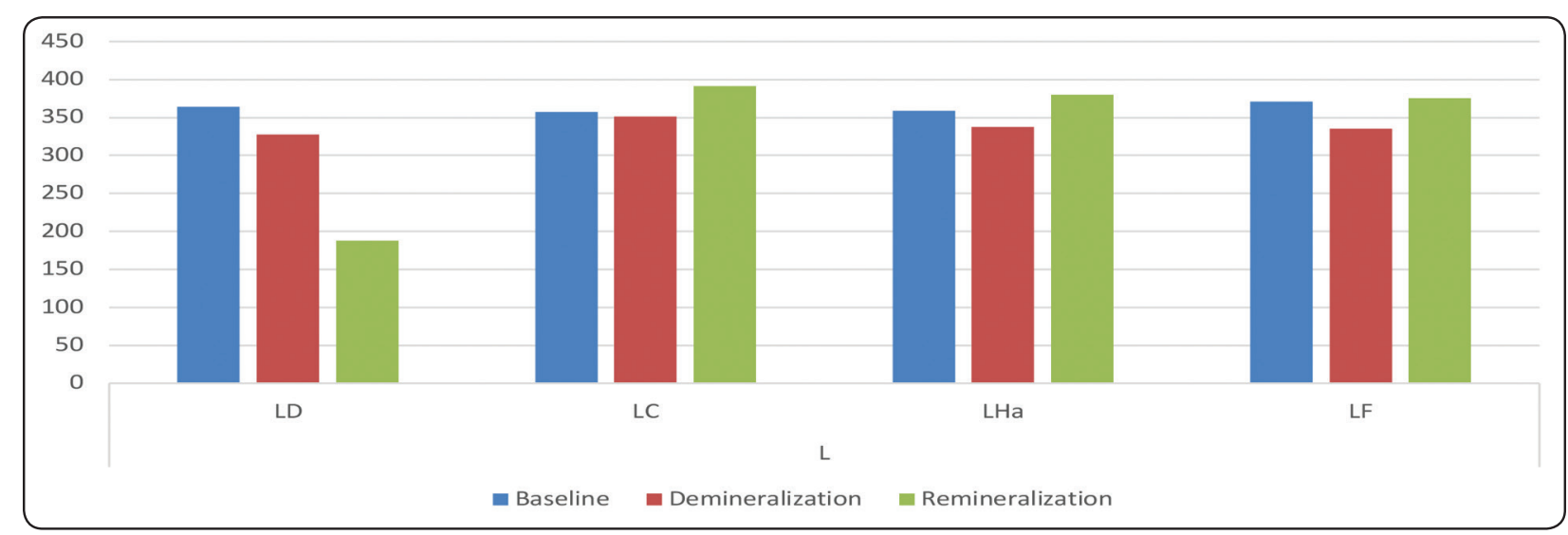

Fig. (15): Mean Vickers hardness number upon bleaching with $1.5 \mathrm{~W}$ and remineralizing with different remineralizing agents. 


\section{DISCUSSION}

The popularity of dental bleaching has grown in the last 10 years as it is perceived as the simplest, most effective, and least destructive method for the treatment of teeth discoloration. Concerns about the potential harmful effects of tooth whitening products have generated many reports and publications since the inception of this treatment ${ }^{[22],[25]}$.

The most known side-effects of vital tooth bleaching are post-operative hypersensitivity and gingival irritation ${ }^{[26]}$. Such effects are related to bleaching agent's concentration, the $\mathrm{pH}$, and application duration. Dental hypersensitivity occurs in about two-thirds of patients during vital bleaching ${ }^{[27]}$. It is principally attributable to the peroxide diffusion into enamel and dentin causing removal of the smear layer and dentin plugs. This leads to dehydration and subsequently moving fluid within the dentinal tubules, resulting in the stimulation of endings of nerves and leading eventually to sensitivity ${ }^{[24]}$.

In the current study, the utilized gel contained $35 \%$ hydrogen peroxide (HP), which is considered as a strong agent of oxidation that is subjected to chemical breakdown and results in increasing reactive oxygen ions, free radicals, and peroxide anions ${ }^{[28]}$. As being reactive and highly unstable, these molecules can oxidize a broad range of organic and inorganic materials such as chromophores ${ }^{[29]}$. Though the aim of any bleaching procedure is teeth whitening without creating any morphological and chemical changes, several side-effects were reported for power bleaching including the presence of porosities, changes in microhardness, the formation of depressions, a reduction in fracture toughness, changes in surface roughness, erosion, alteration of the calcium/phosphate ratio, and decrease in abrasion resistance. The key reason is the enamel structure weakening due to the oxidation of the organic or inorganic elements ${ }^{[30]}$.

Clinicians accelerated the speed of bleaching by activating the oxidation reaction with heat/ light application [15], [31], [32]. It was also found that bleaching using HP in combination with a diode laser irradiation results in improving the effect of bleaching and protecting against any changes in the structure of enamel ${ }^{[34]}$. In some studies, it was indicated that diode laser irradiation can reduce or prevent the surface etching of the enamel ${ }^{[32]}$. This might be attributable to the in-depth activity of the laser-activated bleaching agent, in comparison to the uncertain impact that conventional bleaching has on the surface and depth. The application of diode laser at both wavelengths of 810 and $980 \mathrm{~nm}$ might reduce the extent of enamel surface alteration that happened during bleaching ${ }^{[16]}$. The diode laser bleaching in this study was conducted using two different laser bleaching protocols; 7W laser power for 30s according to the manufacturer instruction ${ }^{[33]}$ and $1.5 \mathrm{~W}$ laser power for $90 \mathrm{~s}{ }^{[16]}$.

In the current study, the ESEM (Environmental Scanning Electron Microscope) was utilized, which differs from the conventional SEM as it requires no sample preparation or gold sputtering, allowing the reuse of same samples throughout the experiment.

After bleaching with 7W laser power, the scanning electromicrographs (SEM) of the enamel surface showed slight irregularities, this was in accordance with a study that found that in comparison with the bleaching treatment without laser irradiation, the professional treatment with bleaching using HP in combination with a diode laser irradiation resulted in improving the impact of bleaching and protecting against any changes in the structure of enamel [34]. Another scanning electron microscopy study pointed out that whitening treatment with either $\mathrm{CP}$ or HP induced various surface alterations, including demineralizing the prisms of enamel, reducing the aprismatic layer, and greater porosity within and between the enamel prisms ${ }^{[35]}$. Moreover, application of $35 \%$ HP had been shown to increase surface roughness by $32 \%$ and increase the erosion of the enamel surface layer by $67 \%{ }^{[36]}$. While, the groups which were bleached with $1.5 \mathrm{~W}$ laser power for 90s showed moderate irregularities on the enamel surfaces which were slightly more than the other group and that may be due to the longer time of exposure to laser irradiation. 
After remineralization, samples treated with potassium oxalate based remineralizing agent showed no deposits; as a sign of remineralization, on the bleached enamel surfaces and had the characteristic fish scale appearance of enamel rods. However, samples which were remineralized using CPP-ACPF (Casein Phosphopeptide-amorphous Calcium Phosphate Fluoride) showed accentuated deposition of granular structures. This was in accordance with the findings of a study that found out that a relatively normal surface of enamel was achieved for groups that were bleached with laseractivation and consequently treated with GC Tooth Mouse $^{\mathrm{TM}}$ and there were not any damage signs and there was evidence of firmly attached amorphous CPP-ACP deposits ${ }^{[11]}$.

Samples treated with Hydroxyapatite nanoparticles (n-HAP) showed superficial deposits of granular structure and that was in accordance with the micrographs of SEM for samples that were treated with the bleaching gel and the remineralizing agent that contains HA (MirasensitiveR hap+), which indicated that there is a normal and even hypermineralized enamel and a precipitated layer is existent on the surface which resembled artificial enamel ${ }^{[11]}$. Moreover, groups remineralized by fluoride based remineralizing agent showed moderate deposition of granular structures on the enamel surface. This was in accordance with a study where rare deposits were shown by samples that were treated with the agent on the basis of amine fluoride ${ }^{[11]}$.

Traditionally, the previous mineral density measuring methods, such as polarizing microscopy, micro-sample's chemical analysis, and contact micro-radiography, were destructive for the specimens [37]. Recently, using EDAX facilitates quantitative measurement of the surface minerals alteration accurately without devastation of the sample which aid in reusing them again ${ }^{[38]}$.

In the present study, there was a decrease in the level of Ca (Calcium) and P (phosphorous) levels after bleaching in almost all samples. This was in accordance with several studies which stated that bleaching combined with laser led the $\mathrm{Ca}$ and $\mathrm{P}$ to have statistically significant losses ${ }^{[1]}$. In another study, the findings revealed that there was a decrease in the mineral content after bleaching with and without light and with $35 \%$ hydrogen peroxide bleaching agent ${ }^{[30]}$. Utilizing LED/laser (470nm/810-830nm) led to a comparable loss of $\mathrm{Ca}$ as in comparison with bleaching without light. After remineralization, Ca level increased in almost all subgroups, except in subgroup (HD) and P level showed an increase in all subgroups except in (HD), (HC) and (HF) where its level decreased. Yet, they showed no statistical significance between phases.

Due to binding to pellicle and plaque, CPPACPF was claimed to stabilize high concentrations of $\mathrm{Ca}$ and $\mathrm{P}$ ions along with fluoride ions at the

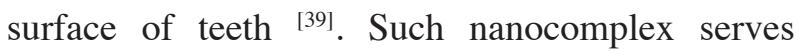
as a reservoir of $\mathrm{Ca}$ and $\mathrm{P}$, which makes itself attached to dental plaque and the surfaces of teeth. Regarding the challenge of acid, $\mathrm{Ca}$ and $\mathrm{P}$ ions are released by the attached $\mathrm{CPP}-\mathrm{ACP}$, resulting into the maintenance of a mineral environment that is supersaturated. Consequently, this leads to the reduction of demineralization and the enhancement of remineralization of enamel as shown by some insitu clinical studies ${ }^{[40]}$.

Being a promising mean of remineralization, n-HAP based remineralizing agent was used in the study. The increased mean of $\mathrm{Ca} / \mathrm{P}$ ratio after remineralizaion of the enamel lesions with fluoride-enhanced hydroxyapatite gel was reported [41] and confirmed the highest values of surface microhardness of enamel specimens treated with HA cream which was statistically significant compared to the control non treated group ${ }^{[42]}$. These results demonstrated an increase in mineral gain. The effect of n-HAP on demineralized enamel may be due to the physically strong adsorption of these nano particles to the acidic etched surface of enamel in in-vitro conditions ${ }^{[43]}$. This was attributable to the effect of charge adsorption which was created between free ions of $\mathrm{Ca}$ and $\mathrm{P}$ in the remineralizing agents and the negative/positive charge domain on etched enamel surfaces ${ }^{[44]}$. 
Finally, a fluoride based remineralizing agent was used as well. Fluoride has always been considered to be one of the best remineralizing agents. This is attributable to calcium phosphate fluorideenhanced precipitation and fluorohydroxyapatite formation in dental tissues ${ }^{[45]}$. In acid solutions, fluorapatite is characterized by being less soluble than hydroxyapatite. In its turn, hydroxyapatite is less soluble than carbonated apatite ${ }^{[46]}$. Referring to previous studies, after bleaching, the immediate topical application of fluoride can remineralize the affected enamel ${ }^{[47]}$.

All studies that examined bleaching impact on the mechanical characteristics of enamel have utilized the hardness test as the key parameter for measuring changes in its characteristics. The microhardness test is appropriate for the determination of small changes in surface, which reveals the bleaching products' impact on enamel ${ }^{[48]}$. After bleaching, microhardness decreased and then increased after remineralization in all subgroups except in HD and LD groups. Although, potassium oxalate was recommended by the manufacturer as a remineralizing agent before and after bleaching, yet, it didn't increase the mineral content and subsequently the microhardness of bleached enamel after remineralization. This was proven in the SEM micrographs where there was no improvement in the enamel defects made due to bleaching. The gel of potassium binoxalate is characterized by its single application and the immediate relief from dentinal hypersensitivity ${ }^{[49]}$, yet, in this study it failed to restore the enamel microhardness. It entailed nitric acid, potassium binoxalate and a patented solution of water. The nitric acid has interactions with the smear layer for precipitating the microcrystals of both potassium nitrate and calcium oxalate. Such crystals can deeply penetrate into the tubules, resulting in sealing the entire dentinal surface with a continual acidresistant complex. The ions of potassium which are existent in such preparation can help in desensitizing nerves.
In previous studies, there was an observation of reduced microhardness after bleaching using a LED/ laser $\left(470 / 830 \mathrm{~nm}, 200 \mathrm{~mW}\right.$ light intensity) ${ }^{[50,51,52]}$. Such changes in enamel's mechanical characteristics have been attributed to alterations of the organic matrix's structural integrity; any distortion in such structure could result in reducing the enamel ability to resist crack propagation and fracture ${ }^{[53]}$. Consistent with these findings, it was revealed that application of $30 \%$ HP led to decreased hardness of enamel due to organic matrix destruction and demineralization ${ }^{[54]}$. However, our increase of microhardness after applying the different remineralizing agents was consistent with the findings of others, where they stated that applying calcium and/or fluoride has the capability of altering the loss of microhardness after treatment ${ }^{[55]}$. In addition, when fluoride is added to the bleaching agent, it will have a positive impact on re-hardening the bleached enamel, resulting in shortening the time required for recovery in comparison with non-fluoride gels ${ }^{[55]}$.

\section{CONCLUSION}

In the context of this in-vitro study's experimental limitations, the following findings were reached:

1- Diode laser bleaching combined with different remineralizing agents has higher effectiveness in achieving an increase in the bleached enamel's microhardness, improving enamel's morphology, and improving the content of calcium and phosphorus.

2- Utilizing remineralizing agents that contain nHAP, CPP-ACP, or fluoride after laser bleaching can enhance enamel microhardness.

3- Potassium oxalate is not recommended to be used as a remineralizing agent after bleaching according to the findings of our study.

4- Laser bleaching should be done following the manufacturer instruction.

Further, more in-vitro and in-vivo studies should be carried out. 


\section{REFERENCES}

1. Calazans FS, Dias KR, Miranda MS. Modified technique for vital bleaching of teeth pigmented by amalgam: a case report. Oper Dent. 2011;36(6):678-82.

2. Sun L, Liang S, Sa Y, Wang Z, Ma X, Jiang T. Surface alteration of human tooth enamel subjected to acidic and neutral 30\% hydrogen peroxide. J Dent. 2011;(39):686-92.

3. Spalding M, Taveira LA, Assis GF. Scanning electron microscopy study of dental enamel surface exposed to $35 \%$ hydrogen peroxide: alone, with saliva, and with $10 \%$ carbamide peroxide. J Esthet Restor Dent. 2003;15(3):154-64.

4. Hayward R, Osman Y, Grobler SR. A clinical study of the effectiveness of a light emitting diode system on tooth bleaching. Open Dent J. 2012;(6):143-7.

5. Kihn PW. Vital tooth whitening. Dent Clin North Am. 2007;51(2):319-31.

6. Cartagena AF, Parreiras SO, Loguercio AD, Reis A, Campanha NH. In-office bleaching effects on the pulp flow and tooth sensitivity - case series. Braz Oral Res. 2015;29(26).

7. Nanjundasetty JK, Ashrafulla M. Efficacy of desensitizing agents on postoperative sensitivity following an in-office vital tooth bleaching: A randomized controlled clinical trial. J Conserv Dent. 2016;19(3):207-11.

8. Josey AL, Meyers IA, Romaniuk K, Symons,A.L. The effect of a vital bleaching technique on enamel surface morphology and the bonding of composite resin to enamel. J.Oral Rehabilit. 1996;23(4):244-250.

9. McCracken MS, Haywood VB. Demineralization effects of 10 percent carbamide peroxide. J.Dent. 1996;24(6):395-8.

10. Heged"us C, Bistey T, Flora-Nagy E, Keszthelyi G, Jenei A. An atomic force microscopy study on the effect of bleaching agents on enamel surface. J.Dent. 1999;27(7):509-15.

11. Coceska E, Gjorgievska E, Coleman NJ, Gabric D, Slipper IJ, Stevanovic M. Enamel alteration following tooth bleaching and remineralization. J Microsc. 2016; 262(3):232-44.

12. Sasaki RT, Catelan A, Bertoldo ES, Venancio PC, Groppo FC, Ambrosano GM. Effect of 7.5\% hydrogen peroxide containing remineralizing agents on hardness, color change, roughness and micromorphology of human enamel. Am J Dent. 2015;28(5):261-7.
13. Chen HP, Chang CH, Liu JK, Chuang SF, Yang JY. Effect of fluoride containing bleaching agents on enamel surface properties. J Dent. 2008;36(9):718-25.

14. Maleknejad F, Ameri H, Kianfar I: Effect of intracoronal bleaching agents on ultrastructure and mineral content of dentin. J Conserv Dent. 2012;15(2):174-7.

15. Anaraki SN, Shahabi S, Chiniforush N, Nokhbatolfoghahaei H, Assadian H, Yousefi B. Evaluation of the effects of conventional versus laser bleaching techniques on enamel microroughness. Lasers Med Sci. 2015;30(3):1013-8.

16. Azarbayjani Z, Kashi T, Erfan Y, Chiniforush N, RakhshanV. Efficacy of diode laser irradiation during dental bleaching in preventing enamel damage caused by bleaching. Dent Res J (Isfahan). 2018; 15(5):320-326.

17. Borges BC, Borges JS, Melo CD, Pinheiro IV, Santos AJ, Braz R. Efficacy of a novel at-home bleaching technique with carbamide peroxides modified by CPP-ACP and its effect on the microhardness of bleached enamel. Oper Dent. 2011;36(5):521-8.

18. Kim Y, Son HH, Yi K, Kim HY, Ahn J, Chang J. The color change in artificial white spot lesions measured using a spectroradiometer. J.Clin.Oral Invest. 2012;17(1):139-46.

19. Jarcho M, Kay JF, Gumaer KI, Doremus RH, Drobeck Hp.J Bioeng. Tissue, cellular and subcellular events at a bone-ceramic hydroxylapatite interface. J Bioeng. 1977;1(2):79-92.

20. Ferraz MP, Monteiro FJ, Manuel CM. Hydroxyapatite nanoparticles: A review of preparation methodologies. J Appl Biomater Func. 2004;2(2):74-80.

21. Ferreira SS, Araújo JL, Morhy ON, Tapety CM, Youssef MN, Sobral MA. The effect of fluoride therapies on the morphology of bleached human dental enamel. Microsc Res Tech. 2011;74:512-16.

22. Cavaili V, Giannini M, Carvalho RM. Effect of carbamide peroxide bleaching agents on tensile strength of human enamel. J Dent Mater. 2004;20(8):733-9.

23. Faraoni-Romano JJ, Turssi CP, Serra MC. Effect of a $10 \%$ carbamide peroxide on wear resistance of enamel and dentine: In situ study. J Dent. 2009;37(4): 273-8.

24. Goldberg M, Grootveld M, Lynch E. Undesirable and adverse effects of tooth-whitening products: A review. Clin Oral Invest. 2009;14(1):1-10.

25. Zimmerman B, Datko L, Cupelli M, Alapati S, Dean D, Kennedy M. Alteration of dentin-enamel mechanical 
properties due to dental whitening treatments. J Mech Behav Biomed Mater. 2010;3(4): 339-46.

26. Ziebolz D, Helms K, Hannig C, Attin T. Efficacy and oral side-effects of two highly concentrated tray-based bleaching systems. Clin Oral Invest. 2007;11(3):267-75.

27. Sulieman M. An overview of tooth-bleaching techniques: chemistry, safety and efficacy. Periodontol 2000 2008;48(1):148-69.

28. Dahl JE, Pallesen U. Tooth bleaching-a critical review of the biological aspects. Crit Rev Oral Biol Med. 2003;14(4): 292-304.

29. Joiner A. The bleaching of teeth: A review of the literature. J Dent. 2006;34(7):412-19.

30. DeMoor RJ, Verheyen J, Verheyen P, Diachuk A, Meire M, De Coster P, De Bruyne M, Keulemans F. Laser teeth bleaching: Evaluation of eventual side effects on enamel and the pulp and the efficiency in vitro and in vivo. Scientific World Journal. 2015; (2015) Article ID 835405.

31. Buchalla W, Attin T. External bleaching therapy with activation by heat, light or laser: A systematic review. Dent Mater. 2007;23(5):586-96.

32. Dostalova T, Jelinkova H, Housova D, Sulc J, Nemec M, Miyagi M. Diode laser-activated bleaching. Braz Dent J. 2004;15:3-8.

33. Almaliky MA. Clinical investigation of $940 \mathrm{~nm}$ diode laser power bleaching: An in vivo study. Journal of laser in medical sciences. 2019;10(1):33-36.

34. Son JH, An JH, Kim BK, Hwang IN. Effect of laser irradiation on crystalline structure of enamel surface during whitening treatment with hydrogen peroxide. J Dent. 2012;40:941-8.

35. Fu B, Hoth Hannig W, Hannig M. Effects of dental bleaching on micro- and nano-morphological alterations of the enamel surface. Am J Dent. 2007;20(1):35-40.

36. Dominguez A, Garcia JA, Costela A, Gomez C. Influence of the light source and bleaching gel on the efficacy of the tooth whitening process. Photomed and Laser Surg. 2011;29:53-59.

37. Zhi QH, Lo EC, Kwok AC: An in vitro study of silver and fluoride ions on remineralization of demineralized enamel and dentin. Aust Dent J, 2013, 58(1): 50-6.

38. Majithia U, Venkataraghavan K, Choudhary P, Trivedi K, Shah S, Virda M. Comparative evaluation of application of different flouride varnishes on artificial early enamel lesions: An in vitro study. Indian J Dent Res. 2016;27(5):521527 .

39. Reynolds E. Casein phosphopeptide-amorphous calcium phosphate: The scientific evidence. Adv Dent Res. 2009;21:25-9.

40. Manton DJ, Walker GD, Cai F, Cochrane NJ, Shen P, Reynolds EC. Remineralization of enamel subsurface lesions in situ by the use of three commercially available sugar-free gums. Int J Pediatr Dent. 2008;18(4):284-90.

41. Pritam M, Padmanabhan S, Chitharanjan AB. An in vitro evaluation of remineralization potential of novamin on artificial enamel sub-surface lesions around orthodontic brackets using energy dispersive X-Ray analysis (EDX). J Clin Diagn Res. 2014;8(11):ZC88-ZC91.

42. Thakur S, Darshana D, Mithra HN. Comparative evaluation of the effect of various remineralizing agents on bleached enamel surface: An in vitro study. J Pharm Sci Innov. 2015;4(6).

43. Hannig M, Hannig C. Nanomaterials in preventive dentistry. Nat Nanotechnol. 2010:5(8):565-9.

44. Wu D, Yang J, Li J, Chen L, Tang B, Chen X, Wu W, Li J. Hydroxyapatite anchored dendrimer for in situ remineralization of human tooth enamel. Biomater. 2013;34: 5036-47

45. TenCate JM. Current concepts on the theories of the mechanism of action of fluoride. Acta Odontol. 1999;57,325329.

46. Shellis RP, Wilson RM. Apparent solubility distributions of hydroxyapatite and enamel apatite. J Colloid Interface Sci. 2004;278(2):325-32.

47. White DJ, Featherstone JD. A longitudinal microhardness analysis of fluoride dentifrice effects on lesion progression in vitro. Caries Res. 1987;32,427-436.

48. Attin T, Kielhassa A, Schwanenberg M, Heilwig E. Effect of fluoride treatment on remineralization of bleached enamel. J oral rehab. 1997;24:282-286.

49. Al-Tayeb D. Management of root-dentine hypersensitivity following non-surgical periodontal therapy: Clinical and scanning electron microscopic study. Egyptian Dent J. 2008;54:1-15.

50. Parreiras SO, Vianna P, Kossatz S, Loguercia AD, Reis A. Effects of light activated in-office bleaching on 
permeability, microhardness, and mineral content of enamel. Oper Dent. 2014;39(5):225-30.

51. Alkhtib A, Manton DJ, Burrow MF, Saher-Samandari S, Palamara JEA, Gross KA. Effects of bleaching agents and Tooth Mousse ${ }^{\mathrm{TM}}$ on human enamel hardness. Vest Clin Dent. 2012;3:1-7.

52. Azer S, Machado C, Sanchez E, Rashid R. Effect of home bleaching systems on enamel nanohardness and elastic modulus.J Dent. 2009;37(3):185-90.
53. Sa Y, Wang Z, Ma X, Lei C, Liang S, Sun L. Investigation of three home-applied bleaching agents on enamel structure and mechanical properties: an in situ study. J Biomed Optic .2012;17(3):035002.

54. Jiang T, Ma X, Wang Y, Zhu Z, Tong H, Hu J. Effects of hydrogen peroxide on human dentin structure. J Dent Res. 2007;86(11):1040-45.

55. Attin T, Betke H, Schippan F, Wiegand A. Potential of fluoridated carbamide peroxide gels to support post-bleaching enamel re-hardening. J Dent. 2007;35(9):755-9. 